\title{
ANALYTICAL REVIEW OF LOSS REDUCTION TECHNIQUES IN INDIAN POWER DISTRIBUTION SECTOR - TECHNO MANAGERIAL APPROACH
}

\author{
Isaac Ramalla ${ }^{1}$, Nithin Namburi ${ }^{2}$ \\ ${ }^{1}$ EEE Department, UPES, Dehradun, India \\ ${ }^{2}$ EEE Department, UPES, Dehradun, India
}

\begin{abstract}
Electrical power is important for economic development and also to improve the quality of life. It will be key input to any activity related to economics in industrial, agricultural, trade, commercial or the service sector. A rapidly developing economy like India faces an ever increasing demand for electrical power. Power distribution is the last stage within the delivery (before retail) of electricity to end user. A distribution system carries power from the transmission system and delivers it to customers. Typically, the distribution system would come with medium voltage $(<50 \mathrm{KV})$ power lines, pole mounted transformers and electrical substations, low voltage $(<1000 \mathrm{~V})$ generally electricity meters and distribution wiring. Distribution is that the important section of electricity price chain because it completes the revenue cycle. Sadly, in India, it's conjointly the weakest ling troubled because it is by poor monetary health, poor assortment efficiencies, poor governance, poor social control practices and lack of responsibility. The distribution sector caters to rural and concrete areas. Post restructuring of the electricity sector, most of the states have engraved out multiple distribution firms with its monopoly space. Presently Republic of India has seven classes of distribution entities The $A T \& C$ losses is one of the major problems of the Indian power sector, we know that India is struggling with the demand-supply gap existing in power sector and trying to recover these gap with different steps, and the AT\&C losses is one of the major milestones of reducing the demand supply gap in the country, also it obligates a burden on the consumers as the T\&D losses are included in the tariff that they are paying. The AT\&C losses has two components technical losses and the commercial losses, the AT\&C losses are $28.44 \%$ (average 2009) in the country, out of them most of the losses are of commercial only.
\end{abstract}

\section{INTRODUCTION}

Due The electricity sector in Republic of India is on the coinciding list of the constitution and therefore both the Centre and also the States having important jurisdiction over the world. Until 1975, every state had a State Electricity Board that was a vertically integrated monopoly liable for generation, transmission and distribution of electricity therein specific state. In 1975, the central government established generation firms like NTPC, NHPC and NEEPCO below the central sector to enhance a lot of required capability addition within the country. Soon after, grid was started to produce interstate and inter-regional transmission connectivity and capacity leading to the event of a national network. However, the world continued to be stricken by demand-supply gaps, high technical and commercial losses notably within the distribution section further as poor monetary and operational performance.

In 1991, the Government of India (GoI) initiated reforms of the facility sector as a part of the larger exercise liberalizing the Indian economy. So as to enhance the supply-demand gap, the GoI permissible the entry of the private sector in electricity generation. There was no law exclusion private sector in electricity distribution even if most of sector was presently below the state governments.
In the mid-1990s, it had been recognized that the mere augmentation of capacity wouldn't be adequate and also the sector needed much more targeted interventions. By the command of the World Bank, govt. of India enacted the state Power Reforms Act in 1995 that entailed the restructuring of the state Electricity Board through a method of purposeful unbundling and also the putting in of the State Electricity Regulatory Commission (SERC) as associate degree freelance regulator for the sector. This model was reforms was derived (sometimes with minor variations) in many different states across the country like state, Karnataka, Uttar Pradesh, Haryana etc. In 1998, the GoI enacted the Electricity Regulative Commissions Act that enabled the states to line up regulative commissions however failed to give the legislative foundation for restructuring the sector. Each restructuring and putting in associate degree ERC continued to be a possibility that states may exercise however wasn't obligatory. It had been solely once the enactment of the EA 2003 was the putting in of a regulative commission in each state created mandatory. However, as way as unbundling was involved, the sole mandatory demand was the separation of the transmission wires from trading for the aim of facilitating open access as a precursor to competition. The distribution firms continued to be native space monopolies although one state-wide distribution company was split into many firms for the sake of up operational potency. 
The EA 2003 provides for the grant of multiple distribution licensees within the same space through independent distribution systems, so as to facilitate competition within the distribution business. Section $62(1)(d)$ specifies that just in case there are quite one distribution licensee within the same space, the SERC could confirm solely the ceiling on the retail tariff so as to push competition. With a read to produce advantages of promoting competition to any or all group of consumers, the second and next in line licensee for distribution within the same space shall have duty to provide to any or all consumers in correspondence with provisions of section 43 of the Indian Electricity Act 2003. The state regulatory commissions needed to control the tariff payable together with connection charges to be collected by a distribution licensee below the provisions in the Act. This can be expected to make sure that more than one distribution licensee doesn't resort to cherry selecting by hard unreasonable affiliation charges from consumers.

\subsection{Electricity Distribution Network Configuration}

Electricity Distribution networks are usually of 2 types:

○ Radial distribution network

○ Interconnected distribution network

A radial distribution network leaves the plant and passes through the network space with no traditional connections to the other supply. This can be usually a protracted rural line with isolated load areas.

An interconnected or ring network is mostly found in additional urban or developed areas and can have multiple connections to different points of sources. These connections are commonly open however permit varied by the operational entity by closing and gap switches. Operations of those switches could also be from a device from far away center or by linemen. The good thing about the interconnected model is that within the event of fault or needed maintenance, a tiny low space of network is isolated and also the remaining will unbroken.

\subsection{Market Structure of Distribution}

Electricity Distribution may be a network business that includes two separate and clearly different businesses

(a) The hardware part comprising the wires and associated transformers meters etc. and

(b) The package part comprising actual offer and also the client interface. In India, distribution firms across most of the states are a local a space| neighborhood $\}$ area monopoly comprising each distribution.

Much of the distribution business in Republic of India is in hand and managed by authorities. though in hand by the govt., these distribution firms are corporatized with the expectation that it would give them the desired autonomy and to include state-of-art social control practices at the same time as they need monopoly right of distribution in their space. However, sure long standing distribution licensees are operational within the personal sector since the introduction of electricity within the country. Examples are Tata Power, R below D (formerly BSES) in Bombay, CESC in urban center and Torrent in Ahmedabad and Surat in Gujarat. The Electricity Act 2003 however permits for the regulator to produce for multiple and parallel distribution licensees within the same space of operation as long as the second licensee constructs its own distribution network.

This still doesn't give for client alternative except at the commencement of the link between the utility and customer nor will it give for switching.For historical reasons, it's solely the town of Bombay, wherever multiple distribution licensees have operated, in their client alternative. The residents of Bombay, the industrial capital of the country, relish $24 X 7$ electricity offer and don't have inverters or voltage stabilizers that are the standard cope mechanisms for electricity shoppers in different components of the country.

Later in 2008, below a Supreme Court judgment, TPC was recognized to be holding a license to provide electricity to even retail consumers in BEST and also the R Infra-D areas. Twenty five TPC began operational as a parallel distribution licensee in these areas. As consumers began to exercise alternative, it became indefensible for TPC to get its own lines and also the geographic area Electricity Regulatory Commission came out with associate degree order permitting the utilization of open access on the distribution network for a wheeling charge and a cross grant surcharge. On 30th November 2011, the Ministry of Power issued a circular stating \{that consumers| that buyers that customers with a capability of one MW and on top of were thoughtabout open access players and also the regulator had no jurisdiction on fixing variable or energy charges for them This notification was reiterated on $3^{\text {rd }}$ August 2012 leading the CERC and also the Forum of Regulators to fits the notification. Presently none of the states have operationalized the notification although several of them have had public hearings on the matter and place it on hold. If this notification will become operationalized, the impact on the structure of electricity distribution would be important as they might not be native space monopolies a minimum of four big customers.

A recent trend in distribution management has been the carving out of franchisee areas notably that comprising of urban areas or urban areas with a rural part associate degreed concern a competitive bid for an input-based franchisee. The target for revenue assortment and T\&D loss reduction is decided through a bidding mechanism. Newly privatized distribution utilities that are joint ventures with the state governments have had mixed results. In state the four distribution firms covering each

\section{POWER TRANSMISSION \\ DISTRIBUTION SYSTEM OF INDIA}

AND

Historically the electricity business is owned by public establishment however beginning within the 1970s country began the method of deregulation and privatization of power sector, resulting in electricity markets. A serious focus of 
those was the elimination of the previous thus referred to as natural monopoly of the generation, transmission and distribution. As a consequence, electricity has become additional of trade goods. The separation has also led to the event of latest word to explain the business units e.g. line company, wire business and Network Company. In Republic of India the facility distribution has continuously been thought-about to be a traditional affair i.e. providing an affiliation, request and revenue realization. Outages or failures on the distribution system have an effect on the buyer straightaway. These systems are additional vulnerable and have less backup capability than bulk power offer system and generation. The matter is, any aggravated by losses, poor voltage rules etc. frequent cycle of power shortages impose restriction on the distribution system.

\subsection{Losses in Electricity Distribution System}

Power generated in power plant goes through giant electrical equipment; advanced networks like Transformers, Overhead Lines, Cables \& Lamps; different equipment's and reaches at the end users. Its unavoidable fact that the Units of electrical energy generated by station don't match with the units consumed to the customers. Some proportion of the power is lost within the Distribution network. This distinction within the generated \& distributed units is understood as Transmission and Distribution loss.

$\square \quad$ Transmission and Distribution losses are the amounts that don't seem to be paid for by users.

$\square \quad \mathrm{T} \& \mathrm{D}$ Losses= (Energy Input to feeder (Kwh)Billed Energy to Consumer (Kwh)) / Energy Input $\mathrm{kWh} \times 100$ ).

$\square \quad$ Distribution is thought of because the poorest link within the entire electricity sector.

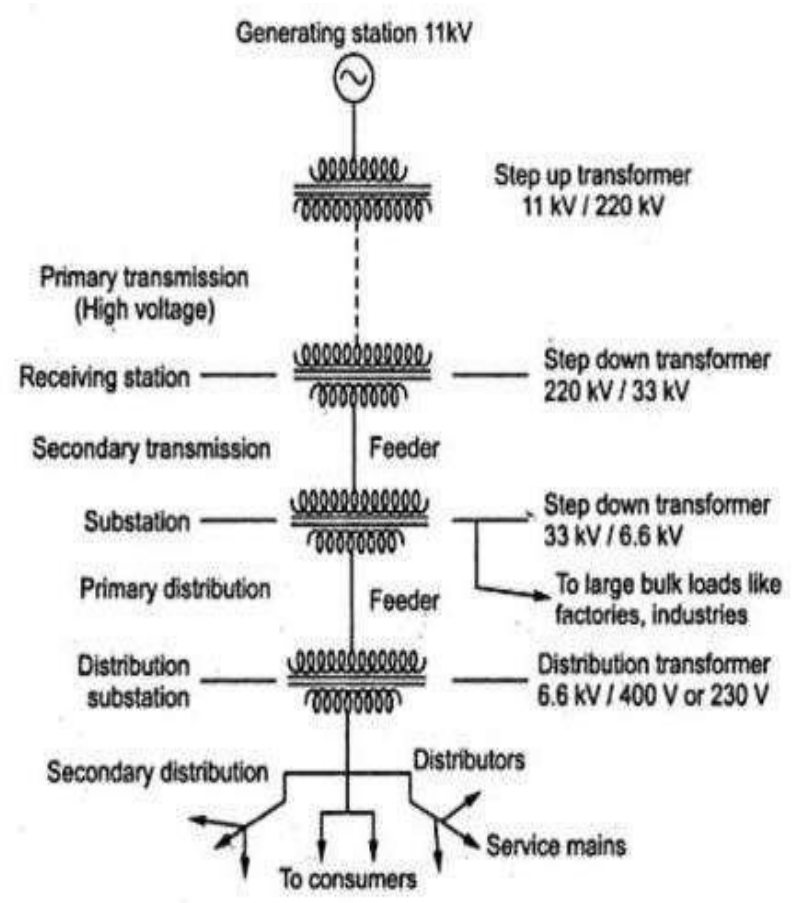

India power transmission and distribution network
Types of Transmission and Distribution Losses

1. Technical Losses

2. Commercial Losses (Non-Technical Losses)

\subsubsection{Technical Losses}

These losses are owing to energy evaporations within the conductors, instrumentality used for cable, electrical device, sub- cable and distribution Line losses and magnetic core losses in transformers.

$\square \quad$ Technical losses are $22.5 \%$, and rely on the network characteristics and therefore the mode of operations.

$\square \quad$ The major quantity of losses in power system grid is in primary distribution and secondary distribution lines. So the first and secondary distribution systems should be correctly planned to confirm among limits.

$\square \quad$ The surprising load increase was reflected within the increase of technical losses on top of the conventional level

$\square \quad$ Losses are inherent to the distribution of electricity and can't be eliminated.

There are the types of Technical Losses.

\subsubsection{Permanent / Fixed Technical losses:}

Fixed losses don't change as per current. These losses are of heat and noise and occur as long as an electrical device is energized. Between $1 / 4$ and $1 / 3$ of technical losses on distribution networks are fixed losses. Fixed losses on a network are influenced within the ways set out below.

Corona Losses.

Leakage Current Losses.

Dielectric Losses.

Open-Circuit Losses.

Losses Caused By Continuous Load of Measure Components

Losses Caused By Continuous Load of Management Elements.

\subsubsection{Variable Technical losses}

Variable losses vary with the number of Electricity distributed and square measure, a lot of exactly, proportional to the square of this. Consequently, a tenth increase in current results in a rise in losses of more than 125th.

$\square \quad$ By increasing the cross-sectional space of cables and conductors for a given load, losses can fall. This results in an immediate decrease between value of losses and price of capital expenditure.

It's been prompt that optimum average utilization rate on a distribution network that considers the price of losses in its style may be as low as thirty per cent.

Joule line losses in lines in every voltage level

Impedance Losses

Losses caused by resistance. 


\section{Major Reasons for Technical Losses:}

Protracted Electric Distribution lines

Inadequate Conductors Size of Distribution lines

Installation of DT far from load centers

Low Power Issue Of Primary And Secondary

Distribution System

Poor Workmanship

Feeder Current and Load Balancing In Feeder

Load factor effect on Losses

Sizing of Transformer and Selection of

Transformer

Balancing Three Phase Loads

Switching Off the Transformers

\subsubsection{Commercial Losses}

Commercial losses are at $16.6 \%$, and associated with meter reading losses, defective meter and error in meter reading, charge of client energy consumption, lack of administration, monetary constraints, and estimating unmetered provider of energy similarly as energy thefts.

\subsubsection{Main Reasons for Non-Technical Losses}

Power Theft

Metering Inaccuracies

Unmetered Losses for terribly little Load

Unmetered supply

Error in Meter Reading

Billing Problems

\subsubsection{Analysis of Loss Reduction Techniques in}

\section{Distribution Sector}

\section{Technical Losses}

Converting lv Line to HV Line

Large commercial / Industrial consumer gets direct Line from Feeder

$\square \quad$ Adopting High Voltage Distribution Service (HVDS) for Agricultural Customer

Adopting Arial Bundle Conductor

Reduce number of Transformer

Utilize Feeder on its Average Capacity

Replacements of old Conductor/Cables

Feeder Renovation / Improvement Program

Industrial / Urban Focus Program

Strictly Follow Preventive Maintenance Program

Preventing Leakages at Insulators

Automatic Voltage booster

Better Management of Distribution Transformers o Addition of Distribution Transformers

- Relocation Of Power Distribution Transformers At Load Centers

- Guarding Against Loss In Transformer

Load Equalization and Load Management

Capacitor Installation

- Across Individual Customers

- At Vantage Points on LT and Eleven Potential Unit Feeders
- At Distribution Electrical Device (On The Secondary Side (LT Side))

- At 33/11 KV Substations

- Improving Joints and Connections

- ARTIFICIAL INTELLIGENCE

Artificial Neural Network

Simulated Algorithm

Ant Formula

\section{Non-Technical Losses: (Managerial Prospective)}

Creating Mapping / Information of Distribution Line

Implementation of Energy Audits Schemes

Mitigating power stealing by Power stealing checking Drives

Replacement of Faulty/Sluggish Energy Meter

Bill collection facility

Reduce Debit areas of Sub Division

Watchdog effect on users.

\subsubsection{Countermeasures for Distribution Loss}

Leveling distribution system masses by \$Leveling distribution system masses by network reconfiguration (for MV, LV system)

Power issue correction by capacitance placement

Install new feeders

Install new transformers

Build a station

Re-conductoring (Replace with larger cross section conductors)

\subsubsection{Leveling of Distribution System Masses by}

\section{Network Re-Configuration}

Some masses within the significant loaded feeder shifted to a different gently loaded feeder

Sectionalizing switchgear allocation for load shift (new interconnection between feeders is also required)

$\square \quad$ Optimal switching allocation may be done by distribution system analysis software system

\subsubsection{Power Issue Correction by Capacitance}

\section{Placement}

Improvement of power issue reduces power flow in a very feeder. Thus, system loss reduction achieved Power issue improved by compensating the reactive power.

\subsubsection{Install New Feeders /Transformers}

\section{/Substations}

significant loaded space to be equipped by new feeder so existing feeder provides less masses (for new feeder install, typically new HV/MV transformer needed) typically new HV/MV transformer needed) 
New station to be inbuilt the middle of high load density spaces different existing feeder provides less masses area so existing feeder provides less masses.

\section{CONCLUSIONS}

Distribution system takes for highest technical and nontechnical losses in power sector. The endeavor of an influence distribution utility ought to cut back leakages by eliminating causes of non-technical losses and by minimizing technical losses. The main factors that contribute to high technical losses are low investments in distribution system, large-scale rural electrification, ad-hoc growth of the system, too several transformation stages, low power issue, caliber of excipient, poor construction and inadequate maintenance of apparatus, improper load management and Distribution Transformers not set at load centers. The factors that contributive to high industrial losses are theft/pilferage by existing client, black affiliation from distribution line by non-customers, incorrect estimation of energy consumption in respect of metered connections, defective metering, meter reading errors, belated request and poor revenue assortment and lack of answerableness. The measures to scale back the technical losses are network reconfiguration, network reconductoring, preventing discharge at insulators, using automatic voltage booster, load reconciliation and load management, capacitor installation etc. The measures to scale back the industrial losses are dominant direct sound by non-customers and customers, pre-paid metering; implementation of IT enabled tools, etc. Technical losses may be reduced to explicit acceptable levels. the suitable technical power loss levels are within the vary of $8.25 \%$ to $15.5 \%$ looking on configuration of the network, physical parameters of the network, level of loading and current in operation voltage of commercial losses.

Cut back request errors: As during this methodology the recharge coupons are issued to the customers for his or her power demand that they'd use for his or her consumption, as a result of this there's no got to generate and deliver the bills which might lead to the reduction of the industrial losses to a great extent.

$\square \quad$ Magnified collection Efficiency: As during this methodology the buyer would take the recharge coupons from the utilities that they need to pay ahead so there's no doubt of the gathering potency but $100 \%$. All the payment would be received by the utilities ahead before the consumption of electricity.

$\square \quad$ Reduced Power Theft: Because the power felony is that the largest contributor of the industrial losses, with the installation of the paid meters the facility felony cases would additionally cut back because the person may solely use the electricity when recharging with the coupons.

$\square \quad$ Consumption as per the requirement: during this methodology it's showed unceasingly on the display of the meter that what's the consumption of the various gadgets and devices employed by the buyer, additionally it displays that what's the number remained to be consumed and when minimum limit the meter can begin creating beeping sound, at now of your time the buyer may manage the load as per the necessity which might lead to the effective use of electricity and an oversized quantity of power is also saved. 